\title{
IMPLEMENTASI JST DALAM MENENTUKAN KELAYAKAN NASABAH PINJAMAN KUR PADA BANK MANDIRI MIKRO SERBELAWAN DENGAN METODE BACKPROPOGATION
}

\author{
Agus Perdana Windarto \\ Program Studi Sistem Informasi, STIKOM Tunas Bangsa Pematangsiantar \\ Jln. Jenderal Sudirman Blok A No. 1,2,3 Pematangsiantar \\ zhantura.gusti@gmail.com
}

\begin{abstract}
The purpose of this study was to develop a decision support system that can facilitate in determining the eligibility of borrowers KUR (Kredit Usaha Rakyat) through predictive use based on existing data and presents various alternative solutions in the selection of a feasibility customers in KUR loan. This study uses Artificial Neural Network applications using Backpropogation method. Criteria used as an assessment in this study is Collateral, Capacity, Loan Application Form, Income and Establishment Business License (Business License). The decision making process consists of two (2) phases where the first phase and pattern recognition, the second phase is forecast feasibility KUR customers. pattern recognition and predictive feasibility KUR customers using different data with the same process using training and testing. The conclusion by the two architectural models 5-2-1 and 5-3-1, obtained 93\% accuracy with 0.0009995807 MSE is the 5-2-1 model architecture. This model is used to predict the feasibility of KUR customers with accuracy> 90\% and MSE truth 0.0009566280 .
\end{abstract}

Keywords: Customer, Neural Networks, Backpropogation, Loans

\begin{abstract}
Abstrak
Tujuan dari penelitian ini adalah untuk mengembangkan sebuah sistem pendukung keputusan yang dapat mempermudah dalam menentukan kelayakan nasabah pinjaman KUR (Kredit Usaha Rakyat) melalui prediksi yang digunakan berdasarkan data yang ada dan menyajikan berbagai solusi alternatif dalam pemilihan kelayakan seorang nasabah dalam melakukan pinjaman KUR. Penelitian ini menggunakan aplikasi Jaringan Saraf Tiruan menggunakan Metode Backpropogation. Kriteria yang digunakan sebagai penilaian pada penelitian ini adalah Collateral, Capacity, Formulir Pengajuan Pinjaman, Penghasilan dan Surat Ijin Usaha Pendirian (SIUP). Proses pengambilan keputusan terdiri dari dua (2) tahap di mana tahap pertama dan pengenalan pola, tahap kedua adalah prediksi kelayakan nasabah KUR. pengenalan pola dan prediksi kelayakan nasabah KUR menggunakan data
\end{abstract}


yang berbeda dengan proses yang sama yang menggunakan data pelatihan (training) dan pengujian data (pengujian). Kesimpulan yang diperoleh dengan dua arsitektur model 5-2-1 dan 5-3-1, diperoleh akurasi 93\% dengan MSE 0,0009995807 adalah arsitektur model 5-2-1. Model ini digunakan untuk memprediksi kelayakan nasabah KUR dengan tingkat akurasi $>90 \%$ dan MSE kebenaran 0,0009566280.

\section{Kata Kunci : Nasabah, Jaringan Sarat Tiruan, Backpropogation, Pinjaman}

\section{PENDAHULUAN}

Pinjaman merupakan sebagai barang atau jasa yang menjadi kewajiban pihak yang satu untuk dibayarkan kepada pihak lain sesuai dengan perjanjian tertulis ataupun lisan. PT. Bank Mandiri Cabang Serbelawan Pematangsiantar adalah sebuah lembaga keuangan yang bergerak dibidang perbankan yang dapat memberikan pinjaman dana kepada masyarakat seperti Kredit Usaha Rakyat (KUR), Kredit Modal Kerja, Kredit investasi dan kredit konsumtif yang dapat meningkatkan produktivitas perekonomian masyarakat. Dalam hal ini pinjaman dana khusus untuk KUR membuat pihak Bank kesulitan dalam penentuan siapa yang layak untuk menerima pinjaman dari pihak bank. Dalam analisa kredit bilamana dilakukan dengan benar dapat berjalan sebagai penyaringan pertama agar Bank tidak terbelit oleh kredit bermasalah. Bila sisi aktiva neraca Bank diperhatikan dengan cermat, maka akan nampak bahwa bagian terbesar dana operasional setiap Bank adalah jumlah kredit yang diberikan. Hal ini menunjukkan bahwa kredit adalah sumber pendapatan terbesar namun sekaligus merupakan risiko terbesar.

Oleh karena itu keberhasilan atau kegagalan Bank dalam mengelola kredit akan sangat berpengaruh terhadap nasib uang milik banyak nasabah jika analisa kredit kurang tepat, maka pemberian kredit tersebut dapat menyulitkan Bank dan bahkan presentase kredit bermasalah pada satu Bank cukup tinggi akan dapat mengganggu likuditas keuangan bank tersebut. Menilai suatu kelayakan terhadap nasabah dalam pemberian pinjaman, bukan hal yang mudah karena melibatkan banyak faktor yang harus dipertimbangkan dan dianalisis tepat, cermat, namun cepat. Hal ini mengingat keamanan dari kredit itu sendiri agar di kemudian hari tidak menimbulkan masalah yang menyulitkan pihak nasabah maupun merugikan pihak bank akibat pengembalian kredit yang kurang lancer, diragukan, dan macet.

Jaringan perambatan galat mundur (Backpropogation) merupakan salah satu algoritma Jaringan Saraf Tiruan yang sering digunakan untuk menyelesaikan masalah-masalah yang rumit dan berkaitan dengan identifikasi input, prediksi, pengenalan pola, dan sebagainya. Backpropogation mempunyai kelebihan dalam mewujudkan sistem yang tahan kerusakan dan konsisten bekerja dengan baik. Dari kelebihan 
Algoritma Backpropogation penulis ingin mengangakat masalah ini menjadi judul penelitian.

\section{METODOLOGI PENELITIAN}

\subsection{Kecerdasan Buatan}

Kecerdasan buatan atau disebut juga Artificial Intelegent (AI) merupakan salah satu bagian dari ilmu komputer yang mempelajari bagaimana membuat mesin (komputer) dapat melakukan pekerjaan seperti dan sebaik yang dilakukan oleh manusia bahkan bisa lebih baik daripada yang dilakukan manusia [1].

\subsection{Jaringan Saraf Tiruan}

Jaringan Saraf Tiruan (JST) merupakan salah satu representasi buatan otak manusia yang selalu mencoba untuk mensimulasikan proses pembelajaran pada otak manusia [2]. Berdasarkan beberapa penelitian di atas yang menekankan pada analisis pemodelan Backpropagation untuk melakukan prediksi dengan objek penelitiannya masing-masing dan menghasilkan kesimpulan bahwa Backpropagation dapat digunakan sebagai problem solving. Neuron adalah unit pemroses informasi yang menjadi dasar dalam pengoperasian Jaringan Saraf Tiruan[3].

\subsubsection{Arsitektur Jaringan Saraf Tiruan (Konfigurasi Jaringan)} menjadi:

Berdasarkan arsitekturnya, model Jaringan Saraf Tiruan digolongkan

1. Jaringan Layar Tunggal (Single Layer Network)

Pada jaringan ini, sekumpulan masukan neuron dihubungkan langsung dengan sekumpulan keluarannya. Sinyal mengalir searah dari layar (lapisan) masukan sampai layar (lapisan) keluaran. Setiap simpul dihubungkan dengan simpul lainnya yang berada diatasnya dan dibawahnya, tetapi tidak dengan simpul yang berada pada lapisan yang sama. Model yang masuk kategori ini antara lain : ADALINE, Hopfield, Perceptron, $L V Q$, dan lain-lain. Pada gambar 1 diperlihatkan arsitektur jaringan layar tunggal dengan $n$ buah masukan $(x 1, x 2, \ldots, x n)$ dan $m$ buah keluaran $(y 1, y 2, \ldots, y m)$.

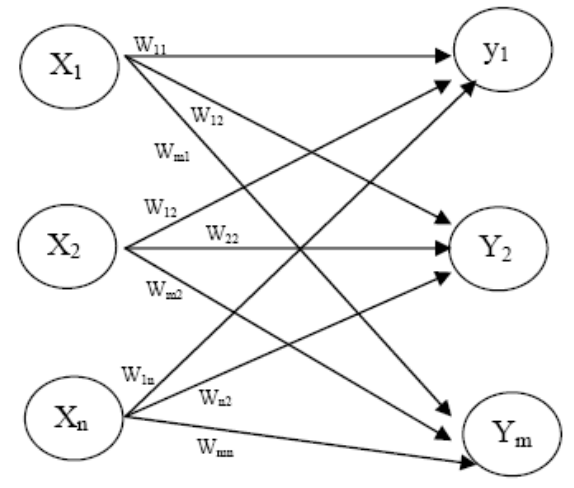

Gambar 1. Jaringan Layar Tunggal 
2. Jaringan Layar Jamak (Multiple Layer Network) Jaringan ini merupakan perluasan dari jaringan layar tunggal. Dalam jaringan ini, selain unit masukan dan keluaran, ada unit-unit lain (sering disebut layar tersembunyi). Dimungkinkan pula ada beberapa layar tersembunyi. Model yang termasuk kategori ini antara lain : MADALINE, backpropagation.Pada gambar 2 diperlihatkan jaringan dengan $\mathrm{n}$ buah unit masukan $(x 1, x 2, \ldots, x n)$, sebuah layar tersembunyi yang terdiri dari $\mathrm{m}$ buah unit $(z 1, z 2, \ldots, z m)$ dan 1 buah unit keluaran.

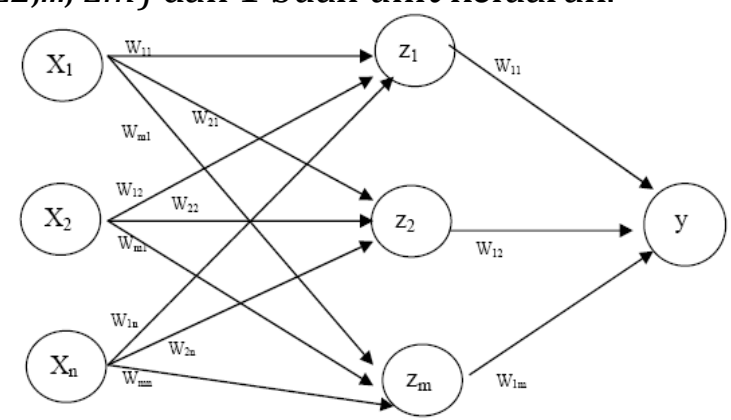

Gambar 2. Jaringan Layar Jamak

3. Jaringan Reccurent (Reccurent Network)

Model jaringan reccurent (reccurent network) mirip dengan jaringan layar tunggal ataupun jamak. Hanya saja, ada simpul keluaran yanng memberikan sinyal pada unit masukan (sering disebut feedback loop). Dengan kata lain sinyal mengalir dua arah, yaitu maju dan mundur. Contoh : Hopfield network, Jordan network, Elmal network [3].

\subsubsection{Permodelan Jaringan Saraf Tiruan}

Sinyal aktivasi menghasilkan output dari neuron. Output ini dapat menjadi hasil dari masalah atau dapat dianggap sebagai masukan bagi neuron lain. Untuk membuat Jaringan Saraf Tiruan diperlukan untuk mengumpulkan jumlah neuron. Neuron diatur pada lapisan. Sebuah jaringan harus memiliki lapisan input (yang membawa nilai-nilai variabel luar) dan lapisan output (prediksi atau hasilnya). Input dan output sesuai dengan sensorik dan Saraf motorik dari tubuh manusia, ada juga dapat lapisan tersembunyi (s) neuron, yang memainkan peran internal jaringan. Semua neuron yang terhubung bersama-sama [4].

\subsubsection{Konsep Dasar Jaringan Saraf Tiruan}

Setiap pola-pola informasi input dan output yang diberikan kedalam JST diproses dalam neuron. Neuron-neuron tersebut terkumpul di dalam lapisan-lapisan yang disebut neuron layers. Lapisan-lapisan penyusun JST tersebut dapat dibagi menjadi 3, yaitu :

1. Lapisan Input

2. Lapisan Tersembunyi

3. Lapisan Output [5].

\subsubsection{Karakteristik Jaringan Saraf Tiruan}

Jaringan Saraf Tiruan memiliki beberapa karakteristik yang unik, diantaranya adalah : 
1. Kemampuan untuk belajar

2. Kemampuan untuk mengeneralisasi

3. Kemampuan untuk menyolusikan permasalahan yang tidak bisa atau kurang baik bila dimodelkan sebagai sistem linier, yang menjadi persyaratan pada beberapa metode peramalan lainnya, seperti model data deret waktu (time series model) [6].

\subsubsection{Pembelajaran Jaringan Saraf Tiruan}

Paradigma/metode pembelajaran/pelatihan Jaringan Saraf Tiruan adalah sebagai berikut :

1. Pembelajaran terawasi (supervised learning)

2. Pembelajaran tak terawasi (unsupervised learning)

3. Gabungan pembelajaran terawasi dan tak terawasi (hybrid) [7].

\subsection{Algoritma Jaringan Saraf Tiruan Backpropagation}

Algoritma Backpropagation merupakan salah satu algoritma yang sering digunakan dalam menyelesaikan masalah-masalah yang rumit. Hal ini dimungkinkan karena jaringan dengan algoritma ini dilatih dengan menggunakan metode belajar terbimbing. Pada jaringan diberikan sepasang pola yang terdiri dari atas pola masukan dan pola yang diinginkan. Algoritma pelatihan jaringan Saraf perambatan galat mundur terdiri atas dua langkah, yaitu perambatan maju dan perambatan mundur. Langkah perambatan maju dan perambatan mundur ini dilakukan pada jaringan untuk setiap pola yang diberikan selama jaringan mengalami pelatihan [5]

\subsubsection{Arsitektur Backpropogation}

Backpropagation memiliki beberapa unit yang ada dalam satu atau lebih lapis tersembunyi. Pada gambar 3 di bawah adalah arsitektur Backpropagation dengan $n$ buah masukan $(x 1, x 2, x 3, \ldots \ldots . . x n)$ ditambah sebuah bias, sebuah lapis tersembunyi yang terdiri dari $j$ unit ditambah sebuah bias, serta $k$ buah unit keluaran [5].

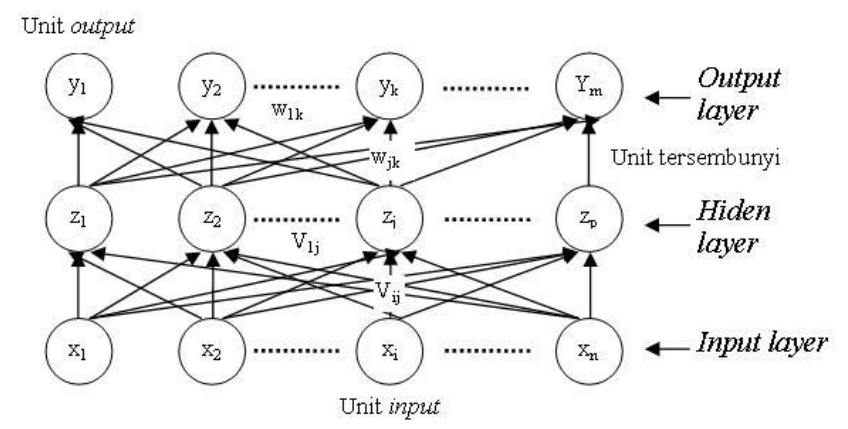

Gambar 3. Arsitektur Backpropogation dengan 3 layer

Simbol-simbol yang digunakan ini tidaklah mutlak, bisa saja berganti dengan simbol-simbol yang lainnya asalkan fungsi logika yang dimaksudkannya tetap sama. Secara sederhana dapat dikatakan bahwa jika output memberikan hasil yang salah, maka penimbang (bobot) dikoreksi supaya errornya (galat) dapat diperkecil dan respon jaringan selanjutnya diharapkan akan lebih mendekati harga yang benar[6]. 


\section{HASIL DAN PEMBAHASAN}

\subsection{Analisis Masalah}

Masalah-masalah yang dapat diselesaikan dengan perangkat lunak ini adalah nantinya antara lain:

1. Diperlukan sistem yang dapat dijadikan sebagai pendukung keputusan dalam menentukan kelayakan nasabah pinjaman KUR pada bank mandiri mikro serbelawan dengan metode backpropogation. Dimana sistem ini nantinya menghasilkan 1 buah parameter output adalah layak atau tidak nya nasabah tersebut melakukan pinjaman KUR pada bank Mandiri mikro serbelawan.

2. Input yang mempengaruhi output adalah data nasabah bank Mandiri mikro serbelawan yang telah melakukan peminjaman KUR yang statusnya diterima dan ditolak berdasarkan keputusan dari pihak bank tersebut. Sampel data yang digunakan sebanyak 30 nasabah. Adapun sampel data nasabah tersebut dapat dilihat pada tabel 4.1 berikut :

Tabel 1. Data nasabah peminjaman KUR (Kredit Usaha Rakyat)

\begin{tabular}{rcllllll}
\hline No & Kode & Collateral & Capacity & Formulir & Penghasilan & SIUP & Status \\
\hline 1 & A14100017 & SHM & Baik & Lengkap & Rp11.000.000 & Ada & Terima \\
2 & A14100060 & Girik & Cukup Baik & Lengkap & Rp5.000.000 & Ada & Terima \\
3 & A14100094 & Girik & Baik & Tidak Lengkap & Rp8.000.000 & Ada & Terima \\
4 & A14100106 & BPKP & Baik & Lengkap & Rp5.900.000 & Ada & Terima \\
5 & A24100002 & Girik & Baik & Lengkap & Rp8.000.000 & Ada & Terima \\
& & & & $\cdot$ & & & \\
& & & &. & & & \\
26 & E14100092 & BPKP & Kurang & Lengkap & Rp1.700.000 & Tidak & Tolak \\
27 & E24100007 & Girik & Baik & Lengkap & Rp8.000.000 & Ada & Terima \\
29 & E24100034 & Girik & Baik & Lengkap & Rp4.300.000 & Ada & Terima \\
30 & E34100025 & BPKP & Cukup Baik & Lengkap & Rp1.100.000 & Ada & Terima \\
\hline
\end{tabular}

Sumber : KUR Bank Mandiri Mikro Serbelawan Pematangsiantar

\subsection{Penetapan Masukan (Input) dan Keluaran (Output)}

Data nasabah peminjaman KUR pada Bank Mandiri mikro serbelawan selanjutnya akan diolah oleh Jaringan Saraf Tiruan dengan metode backpropogation. Agar data dapat dikenali oleh Jaringan Saraf Tiruan, maka data harus direpresentasikan ke dalam bentuk numerik antara $0 \mathrm{~s} / \mathrm{d} 1$, dimana data masukan (input) adalah data nasabah peminjaman KUR dan data keluaran (output) yang merupakan hasil dari prediksi kelayakan nasabah yang melakukan peminjaman KUR yang diperoleh dari model arsitektur terbaik pada saat penentuan pola terbaik. Hal ini dikarenakan jaringan menggunakan fungsi aktivasi sigmoid biner (logsig) yang rangenya dari 0 sampai 1 . Nilai-nilai yang digunakan diperoleh berdasarkan kategori 
dari masing-masing variabel selain juga untuk memudahkan mengingat dalam pendefinisiannya.

\subsubsection{Penetapan Masukan (Input)}

Variabel penentuan pola dalam Menentukan Kelayakan Nasabah Pinjaman KUR Pada Bank Mandiri Mikro Serbelawan Dengan Metode Backpropogation merupakan kriteria yang menjadi acuan dalam pengambilan keputusan pada penilaian dengan menggunakan Jaringan Saraf Tiruan. Adapun variabel masukan JST tentang Menentukan Kelayakan Nasabah Pinjaman KUR Pada Bank Mandiri Mikro Serbelawan dapat dilihat dari tabel 2 berikut :

\section{Tabel 2. Daftar kriteria variabel kelayakan pinjaman KUR}

\begin{aligned} & \hline No \\ & \hline 1 Collateral \\ & 2 Capacity \\ & 3 Formuliaian Pengajuan Pinjaman \\ & 4 Penghasilan \\ & 5 Surat Ijin Usaha Pendirian (SIUP) \\ & \hline\end{aligned}

Sumber : KUR Bank Mandiri

Tabel 3. Daftar bobot kriteria variabel kelayakan pinjaman KUR

\begin{tabular}{|c|c|c|c|}
\hline No & Penilaian & Kriteria & Bobot \\
\hline \multirow[t]{3}{*}{1} & Collateral & Baik (Girik) & 0.9 \\
\hline & & Cukup Baik (SHM) & 0.75 \\
\hline & & Kurang $(B P K P)$ & 0.2 \\
\hline \multirow[t]{3}{*}{2} & Capacity & Baik & 0.9 \\
\hline & & Cukup Baik & 0.75 \\
\hline & & Kurang & 0.2 \\
\hline \multirow[t]{2}{*}{3} & Formulir Pengajuan Pinjaman & Lengkap & 0.9 \\
\hline & & Tidak Lengkap & 0.1 \\
\hline \multirow[t]{3}{*}{4} & Penghasilan & Lebih $(>10$ juta) & 0.9 \\
\hline & & Cukup (>1 juta) & 0.75 \\
\hline & & Kurang $(<1$ juta $)$ & 0.2 \\
\hline \multirow[t]{2}{*}{5} & Surat Ijin Usaha Pendirian (SIUP) & Ada & 0.9 \\
\hline & & Tidak Ada & 0.1 \\
\hline
\end{tabular}

\subsubsection{Penetapan Keluaran (Output)}

Adapun data target adalah layak atau tidaknya nasabah dalam melakukan pinjaman KUR. Bobot 0 menunjukkan nasabah tidak layak mendapatkan pinjaman KUR dan bobot 1 menunjukkan nasabah layak mendapatkan pinjaman KUR. Data target dapat dilihat pada tabel 4.

Tabel 4. Data Target

\begin{tabular}{clcc}
\hline No & & Keterangan & Bobot \\
\hline 1 & Layak & 1 \\
2 & Tidak layak & 0 \\
\hline
\end{tabular}

Prediksi Kelayakan KUR dengan Backpropogation(Agus Perdana Windarto) | 18 


\subsection{Pengolahan Data}

Pengolahan data yang dilakukan adalah mengubah data nasabah peminjaman KUR berdasarkan bobot yang sudah ditentukan seperti pada Tabel 3. Data ini nantinya akan diolah sesuai dengan kebutuhan yaitu dengan membuat suatu pola arsitektur terbaik menggunakan Jaringan Saraf Tiruan dengan backpropogation. Pola terbaik yang didapat dengan bersumberkan data nasabah peminjaman KUR yang akan dilanjutkan dengan memprediksi kelayakan nasabah peminjaman KUR. Proses prediksi dilakukan dengan memasukkan data nasabah peminjaman KUR. Dari prediksi itu akan dilihat berapa nilai error minimum untuk menentukan prediksi yang benar atau tidak berdasarkan ketentuan yang ditetapkan pada tabel 6. Dari hasil pengolahan data yang dilakukan, maka data yang sudah diolah seperti yang terdapat pada Tabel 5 berikut:

\section{Tabel 5. Data Transformasi Nasabah Peminjaman KUR Bank Mandiri}

\begin{tabular}{cccccccc}
\hline \multirow{2}{*}{ No } & \multirow{2}{*}{ Kode } & $\begin{array}{c}\text { X1 } \\
\text { Collateral }\end{array}$ & $\begin{array}{c}\text { X2 } \\
\text { Capacity }\end{array}$ & $\begin{array}{c}\text { X3 } \\
\text { Formulir }\end{array}$ & $\begin{array}{c}\text { X4 } \\
\text { Penghasilan }\end{array}$ & $\begin{array}{c}\text { X5 } \\
\text { SIUP }\end{array}$ & Target \\
\hline 1 & A14100017 & 0,75 & 0,9 & 0,9 & 0,1 & 0,9 & 1 \\
2 & A14100060 & 0,90 & 0,75 & 0,9 & 0,75 & 0,9 & 1 \\
3 & A14100094 & 0,90 & 0,9 & 0,1 & 0,75 & 0,9 & 1 \\
4 & A14100106 & 0,20 & 0,9 & 0,9 & 0,75 & 0,9 & 1 \\
5 & A24100002 & 0,90 & 0,9 & 0,9 & 0,75 & 0,9 & 1
\end{tabular}

\begin{tabular}{llllllll}
26 & E14100092 & 0,20 & 0,2 & 0,9 & 0,75 & 0,1 & 0 \\
27 & E24100007 & 0,90 & 0,9 & 0,9 & 0,75 & 0,9 & 1 \\
28 & E24100034 & 0,90 & 0,9 & 0,9 & 0,75 & 0,9 & 1 \\
29 & E34100025 & 0,20 & 0,75 & 0,9 & 0,75 & 0,9 & 1 \\
30 & E44100051 & 0,75 & 0,2 & 0,1 & 0,75 & 0,1 & 0 \\
\hline
\end{tabular}

Pada tabel 5, hasil yang diinginkan pada tahap ini adalah terdeteksinya suatu nilai untuk penentuan pola terbaik dalam menentukan kelayakan nasabah pinjaman KUR Pada Bank Mandiri Mikro Serbelawan Dengan Metode Backpropogation. Adapun hasil yang dimaksud adalah sebagai berikut:

Tabel 6. Data Kategorisasi

\begin{tabular}{lll}
\hline No & Keterangan & Error Minimum \\
\hline 1 & Layak & $0.05-0.001$ \\
2 & Tidak Layak & $0.05-0.001$ \\
\hline
\end{tabular}

\subsection{Pelatihan Data dengan Arsitektur 5-2-1}

Data yang akan digunakan sebagai pelatihan Jaringan Saraf Tiruan dengan arsitektur 5-2-1, dengan data pelatihan sebanyak 15 pola dari pola 1 s/d pola 15. Setelah dilakukan perulangan maka ditemukan error minimum pada epoch 31254 seperti pada gambar 4. 


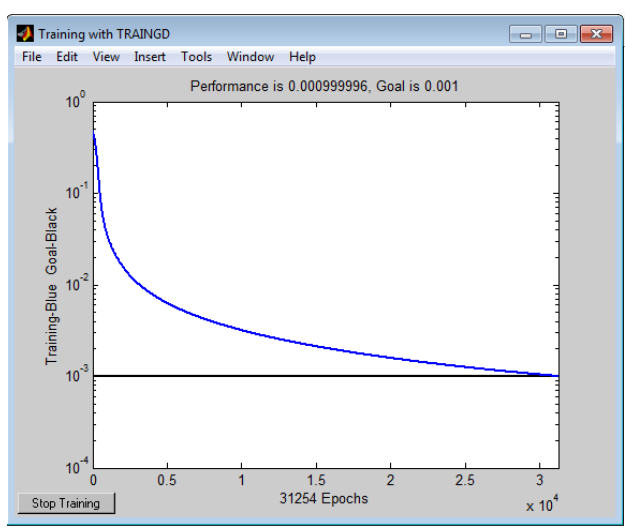

\section{Gambar 4. Pelatihan Arsitektur 5-2-1 Mencapai Goal}

Untuk hasil yang lebih rinci dan mengetatahui output dan error dapat dilihat pada tabel 7.

Tabel 7. Hasil dan Error Data Input Pelatihan dengan Model 5-2-1

\begin{tabular}{rlcccc} 
No & Data & Target & JST & Error & SSE \\
\hline 1 & Data 1 & 1 & 0,994 & 0,0056 & 0,0000313600 \\
2 & Data 2 & 1 & 0,976 & 0,0239 & 0,0005712100 \\
3 & Data 3 & 1 & 0,962 & 0,0382 & 0,0014592400 \\
4 & Data 4 & 1 & 0,957 & 0,0433 & 0,0018748900 \\
5 & Data 5 & 1 & 0,976 & 0,0238 & 0,0005664400 \\
6 & Data 6 & 1 & 0,976 & 0,0245 & 0,0006002500 \\
7 & Data 7 & 1 & 0,975 & 0,0247 & 0,0006100900 \\
8 & Data 8 & 0 & 0,025 & $-0,0246$ & 0,0006051600 \\
9 & Data 9 & 0 & 0,061 & $-0,0609$ & 0,0037088100 \\
10 & Data 10 & 1 & 0,976 & 0,0236 & 0,0005569600 \\
11 & Data 11 & 1 & 0,976 & 0,0236 & 0,0005569600 \\
12 & Data 12 & 1 & 0,976 & 0,0245 & 0,0006002500 \\
13 & Data 13 & 0 & 0,033 & $-0,0328$ & 0,0010758400 \\
14 & Data 14 & 0 & 0,027 & $-0,0272$ & 0,0007398400 \\
15 & Data 15 & 0 & 0,038 & $-0,0379$ & 0,0014364100 \\
\hline & & & & Total & $\mathbf{0 , 0 1 4 9 9 3 7 1 0 0}$ \\
& & & & MSE & $\mathbf{0 , 0 0 0 9 9 9 5 8 0 7}$ \\
\hline
\end{tabular}

\subsection{Pengujian Data dengan Arsitektur 5-2-1}

Setelah dilakukan pelatihan dengan pola arsitektur 5-2-1, maka dilanjutkan dengan pengujian dengan data sebanyak 15 data dari data $16 \mathrm{~s} / \mathrm{d}$ data 30. Berikut adalah hasil pengujian dengan 15 data pengujian dengan pola pengujian 5-2-1. Data hasil pengujian dapat dilihat pada tabel 8 sebagai berikut:

Tabel 8. Hasil dan Error Data Input Pengujian dengan Model 5-2-1

\begin{tabular}{rcccccc} 
No & Data & Target & JST & Error & SSE & Hasil \\
\hline 1 & Data 16 & 0 & 0,0272 & $-0,0272$ & 0,0007398400 & Benar \\
2 & Data 17 & 1 & 0,9567 & 0,0433 & 0,0018748900 & Benar
\end{tabular}


Jurnal Sains Komputer \& Informatika (J-SAKTI)

Volume (1) No. 1 Maret 2017

ISSN:2548-9771/EISSN: 2549-7200

http://ejurnal.tunasbangsa.ac.id/index.php/jsakti

\begin{tabular}{rcccccc}
\hline No & Data & Target & JST & Error & SSE & Hasil \\
\hline 3 & Data 18 & 1 & 0,9764 & 0,0236 & 0,0005569600 & Benar \\
4 & Data 19 & 0 & 0,0272 & $-0,0272$ & 0,0007398400 & Benar \\
5 & Data 20 & 1 & 0,9764 & 0,0236 & 0,0005569600 & Benar \\
6 & Data 21 & 0 & 0,0246 & $-0,0246$ & 0,0006051600 & Benar \\
7 & Data 22 & 0 & 0,0246 & $-0,0246$ & 0,0006051600 & Benar \\
8 & Data 23 & 1 & 0,9764 & 0,0236 & 0,0005569600 & Benar \\
9 & Data 24 & 0 & 0,0403 & $-0,0403$ & 0,0016240900 & Benar \\
10 & Data 25 & 0 & 0,0272 & $-0,0272$ & 0,0007398400 & Benar \\
11 & Data 26 & 0 & 0,0246 & $-0,0246$ & 0,0006051600 & Benar \\
12 & Data 27 & 1 & 0,9762 & 0,0238 & 0,0005664400 & Benar \\
13 & Data 28 & 1 & 0,9762 & 0,0238 & 0,0005664400 & Benar \\
14 & Data 29 & 1 & 0,9428 & 0,0572 & 0,0032718400 & Salah \\
15 & Data 30 & 0 & 0,0272 & $-0,0272$ & 0,0007398400 & Benar \\
\hline & & & Total & 0,0143494200 & 93\% \% \\
\hline
\end{tabular}

\subsection{Pelatihan Data dengan Arsitektur 5-3-1}

Data yang akan digunakan sebagai pelatihan Jaringan Saraf Tiruan dengan arsitektur 5-3-1, dengan data pelatihan sebanyak 15 pola dari pola 1 s/d pola 15. Setelah dilakukan perulangan maka ditemukan error minimum pada epoch 23014 seperti pada gambar 5

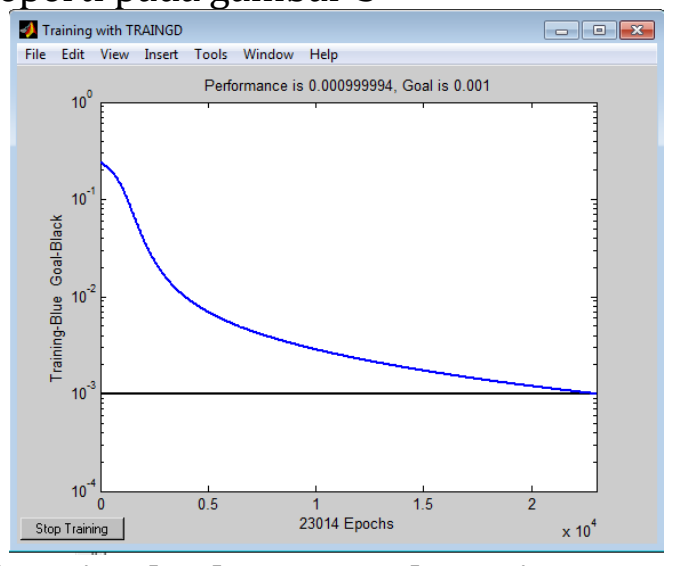

Gambar 5 Pelatihan Arsitektur 5-3-1 Mencapai Goal

Untuk hasil yang lebih rinci dan mengetatahui output dan error dapat dilihat pada tabel 9.

Tabel 9. Hasil dan Error Data Input Pelatihan dengan Model 5-3-1

\begin{tabular}{rlcccc}
\hline No & Data & Target & JST & Error & SSE \\
\hline 1 & Data 1 & 1 & 0,9707 & 0,0293 & 0,0008584900 \\
2 & Data 2 & 1 & 0,9611 & 0,0389 & 0,0015132100 \\
3 & Data 3 & 1 & 0,9804 & 0,0196 & 0,0003841600 \\
4 & Data 4 & 1 & 0,9417 & 0,0583 & 0,0033988900
\end{tabular}

Prediksi Kelayakan KUR dengan Backpropogation(Agus Perdana Windarto) | 21 
Jurnal Sains Komputer \& Informatika (J-SAKTI)

Volume (1) No. 1 Maret 2017

ISSN:2548-9771/EISSN: 2549-7200

http://ejurnal.tunasbangsa.ac.id/index.php/jsakti

\begin{tabular}{rlrrrr}
5 & Data 5 & 1 & 0,9840 & 0,0160 & 0,0002560000 \\
6 & Data 6 & 1 & 0,9899 & 0,0101 & 0,0001020100 \\
7 & Data 7 & 1 & 0,9801 & 0,0199 & 0,0003960100 \\
8 & Data 8 & 0 & 0,0177 & $-0,0177$ & 0,0003132900 \\
9 & Data 9 & 0 & 0,0656 & $-0,0656$ & 0,0043033600 \\
10 & Data 10 & 1 & 0,9888 & 0,0112 & 0,0001254400 \\
11 & Data 11 & 1 & 0,9888 & 0,0112 & 0,0001254400 \\
12 & Data 12 & 1 & 0,9899 & 0,0101 & 0,0001020100 \\
13 & Data 13 & 0 & 0,0027 & $-0,0027$ & 0,0000072900 \\
14 & Data 14 & 0 & 0,0140 & $-0,0140$ & 0,0001960000 \\
15 & Data 15 & 0 & 0,0541 & $-0,0541$ & 0,0029268100 \\
\hline & & & & Total & 0,0150084100 \\
& & & & MSE & 0,0010005607 \\
\hline
\end{tabular}

\subsection{Pengujian Data dengan Arsitektur 5-3-1}

Setelah dilakukan pelatihan dengan pola arsitektur 5-3-1, maka dilanjutkan dengan pengujian dengan data sebanyak 15 data dari data $16 \mathrm{~s} / \mathrm{d}$ data 30, Berikut adalah hasil pengujian dengan 15 data pengujian dengan pola pengujian 5-3-1. Data hasil pengujian dapat dilihat pada tabel 10 sebagai berikut:

Tabel 10. Hasil dan Error Data Input Pengujian dengan Model 5-2-1

\begin{tabular}{rcccccc}
\hline No & Data & Target & JST & Error & SSE & Hasil \\
\hline 1 & Data 16 & 0 & 0,0140 & $-0,0140$ & 0,0001960000 & Benar \\
2 & Data 17 & 1 & 0,9417 & 0,0583 & 0,0033988900 & Salah \\
3 & Data 18 & 1 & 0,9888 & 0,0112 & 0,0001254400 & Benar \\
4 & Data 19 & 0 & 0,0140 & $-0,0140$ & 0,0001960000 & Benar \\
5 & Data 20 & 1 & 0,9888 & 0,0112 & 0,0001254400 & Benar \\
6 & Data 21 & 0 & 0,0177 & $-0,0177$ & 0,0003132900 & Benar \\
7 & Data 22 & 0 & 0,0177 & $-0,0177$ & 0,0003132900 & Benar \\
8 & Data 23 & 1 & 0,9888 & 0,0112 & 0,0001254400 & Benar \\
9 & Data 24 & 0 & 0,3680 & $-0,3680$ & 0,1354240000 & Salah \\
10 & Data 25 & 0 & 0,0140 & $-0,0140$ & 0,0001960000 & Benar \\
11 & Data 26 & 0 & 0,0177 & $-0,0177$ & 0,0003132900 & Benar \\
12 & Data 27 & 1 & 0,9840 & 0,0160 & 0,0002560000 & Benar \\
13 & Data 28 & 1 & 0,9840 & 0,0160 & 0,0002560000 & Benar \\
14 & Data 29 & 1 & 0,9225 & 0,0775 & 0,0060062500 & Salah \\
15 & Data 30 & 0 & 0,0140 & $-0,0140$ & 0,0001960000 & Benar \\
\hline & & & & Total & 0,1474413300 & 80\% \\
& & & & 0,0098294220 & \\
\hline
\end{tabular}

Dari tabel diatas dapat disimpulkan bahwa model 5-2-1 adalah model terbaik yang memiliki tingkat akurasi $93 \%$. Model ini nantikan akan digunakan untuk memprediksi kelayakan nasabah pinjaman KUR pada Bank Mandiri Mikro Serbelawan. 


\section{KESIMPULAN}

Berdasarkan uraian pad bab-bab sebelumnya, maka pada penelitian ini dapat ditarik beberapa kesimpulan sebagai berikut :

a. Metode Jaringan Saraf Tiruan dapat diterapkan dalam memprediksi kelayakan nasabah pinjaman KUR pada Bank Mandiri cabang serbelawan dengan akurasi 93\%

b. Dari kedua arsitektur yang digunakan dalam menentukan pola terbaik guna melakukan prediksi, diperoleh hasil model 5-2-1 lebih baik dibandingkan 5-3-1 dengan tingkat MSE lebih keci yakni 0,0009566280

c. Metode Jaringan Saraf Tiruan mempunyai sifat yang adaptif yaitu jaringan berusaha mencapai kestabilan kembali untuk mencapai output yang diharapkan. Hal ini disebabkan karena adanya proses belajar dengan penyesuaian bobot-bobot koneksi

\section{DAFTAR PUSTAKA}

[1] M. Dahria, "Pengantar Kecerdasan Buatan ( Artificial Intelligence)," Pengantar Kecerdasan Buatan, vol. 5, no. 2, pp. 1-5, 1991.

[2] E. Marleni Anike, Suyoto, "Pengembangan sistem jaringan syaraf tiruan dalam memprediksi jumlah dokter keluarga menggunakan Backpropagation," vol. 2012, no. Sentika, pp. 209-216, 2012.

[3] D. Maru'ao, "Neural Network Implementation in Foreign Exchange Kurs Prediction," Gunadarma Univ. Fac. Ind. ..., 2010.

[4] A. Gupta and M. Shreevastava, "Medical Diagnosis using Back propagation Algorithm," Int. J. Emerg. Technol. Adv. Eng., vol. 1, no. 1, pp. 55-58, 2011.

[5] Z. A. Matondang, "Jaringan Syaraf Tiruan Dengan Algoritma Backpropagation Untuk Penentuan Kelulusan Sidang Skripsi” Pelita Inform. Budi Darma, vol. IV, no. 1, 2013.

[6] A. Jumarwanto, "Aplikasi Jaringan Saraf Tiruan Backpropagation Untuk Memprediksi Penyakit Tht Di Rumah Sakit Mardi Rahayu Kudus," J. Tek. Elektro, vol. 1, no. 1, pp. 11-21, 2009.

[7] W. M. Dessy and A. Irawan, "Perbandingan Metode Jaringan Syaraf Tiruan Backpropagation Dan Learning Vector Quantization Pada Pengenalan Wajah," J. Komput. dan Inform., vol. 1, no. 1, pp. 45-51, 2012. 